\title{
ВАРИАНТЫ МОНИТОРИНГА ДЕТЕЙ С САХАРНЫМ ДИАБЕТОМ 1 ТИПА \\ В ПЕРМСКОМ КРАЕ
}

${ }^{1}$ Худорожкова О.М., ${ }^{2}$ Смирнова Е.Н.

${ }^{1}$ ГБУЗ Пермского края «Краевая детская клиническая больница», Пермь

${ }^{2}$ ФББОУ ВО «Пермский государственный медицинский университет имени академика Е.А. Вагнера» Минздрава России, Пермь

Актуальность: Амбулаторная помощь после выписки пациента из специализированного отделения осуществляется по месту жительства. Однако не все дети наблюдаются врачами-эндокринологами в связи с дефицитом специалистов и удаленностью многих населенных пунктов от краевого центра. Во многих странах наблюдение детей с сахарным диабетом 1 типа (СД1) через интернет является обычной практикой.

Цель. Сравнить эффективность различных вариантов наблюдения эндокринологами за детьми с СД1 в течение первого года заболевания.

Материалы и методы. Проанализированы данные анамнеза, клинических и инструментальных методов исследования 94 пациентов с впервые диагностированным СД1, разделенных на 3 группы. В 1 группе ( $\mathrm{n}=34$, контрольная) пациенты наблюдались по стандартной программе: дети из районов края, в отсутствии эндокринолога посещали консультативный прием специалиста в КДКБ 1 раз в 3 месяца; проживающие в городах, обеспеченных специалистами, 1 раз в месяц; во 2 группе (n=36) дети наблюдались дистанционно с использованием интернет-технологий: электронная почта, социальные сети; в 3 - наблюдение детей $(\mathrm{n}=24)$ осуществлялось ежемесячно районным детским эндокринологом. Через 6 и 12 месяцев проводился опрос всех пациентов и родителей на выживаемость знаний, полученных при обучении в Школе диабета и оценка степени компенсации по гликемии и НbА1с. Для оценки статистической значимости различий количественных показателей использовался t-критерий Стьюдента и критерий Манна - Уитни. Статистическая значимость различий считалась достоверной при вероятности справедливости нулевой гипотезы менее 0,05 .

Результаты. Уровень $\mathrm{HbA1c}$ был достоверно ниже в группе дистанционного наблюдения эндокринологом как через $6(28,4 \%)$, так и $12(26,4 \%)$ месяцев $(\mathrm{p} \leq 0.05)$. Большинство наблюдаемых пациентов измеряли сахар крови от 4 до 7 раз в день. Рекомендации по ведению дневника самоконтроля выполняли более 70\% пациентов 2 группы. 64,7\% и 66,7\% пациентов из 1 и 3 групп пренебрегали этим правилом. При анализе данных гликемии отмечались лучшие значения во 2 группе по сравнению с аналогичными показателями в 1 и 3 группах $(\mathrm{p} \leq 0,05)$. Отсутствовали гипогликемические состояния в течение 1 -х месяцев заболевания у 13,9\% и 12,5\% опрошенных из 2 и 3 групп, и у 23,5\% пациентов 1 группы. Частота эпизодов гипергликемии выше 13 ммоль/л более 2 раз в неделю также была ниже во 2 группе. Пациенты, имеющие возможность общения с эндокринологом, имели больше навыков в правильной коррекции как гипо-, так и гипергликемии. Анализ виртуальных обращений пациентов 2 группы выявил наибольшие трудности при лечении диабета в вопросах коррекции гипергликемии при различных ситуациях, изменение доз инсулина при повторяющихся гипогликемиях, а также технике введения инсулина.

\section{Выводы:}

1. Пациенты, имеющие возможность регулярно наблюдаться эндокринологом лучше ориентируются в вопросах питания, коррекции доз инсулина, физических нагрузок, реже имеют эпизоды гипогликемий и гипергликемий и лучшую компенсацию на 1м году заболевания.

2. Результаты наблюдения детей с сахарным диабетом 1 типа врачом-эндокринологом с помощью интернет-технологий сравнимы по эффективности с мониторингом при очном ежемесячном 
контакте по показателям компенсации и могут быть предложены для территорий, отдаленных от специализированных лечебных учреждений.

Ключевые слова: Сахарный диабет; дети и подростки; дистанционное наблюдение; Школа диабета 